\title{
Jordanian Science Teachers' Perspectives on Obstacles of Differentiated Instruction
}

\author{
Dr. Jehad. Abed R.M. Turkey, Educational Psychology Department / College of Educational Sciences, \\ Tafila Technical University P.O. Box:179.Zip Code: 66110.Jordan, jturki@ttu.edu.jo \\ Prof. Dr. Mohammad S. Al-rsa'I, Curriculum and Instruction department/College of Educational Sciences, \\ Al-Hussien bin Talal University-Jordan, rsaaie@ahu.edu.jo \\ Dr. Khaled abu tayeh, Curriculum and Instruction department/ College of Educational Sciences, Al- \\ Hussien bin Talal University-Jordan, k-abutayeh@ahu.edu.jo
}

\begin{abstract}
Differentiated instruction is a philosophy about teaching and learning based on the main assumption that students who are the same age differ in their readiness, interests, styles of learning, experiences and their life circumstances. This study aims to investigate the Jordanian science teachers' perspectives on differentiated instruction. Qualitative data were collected via face-to-face interviewing (18) Jordanian science teachers, who were join training in differentiated instruction. The results of the study show that most of the science teachers (67\%) indicated that the opportunity to implement differentiated instruction is poor, they believe that differentiated instruction can cause them to lose control on the educational situation This could be attributed to the classroom environment prevalent in the schools of Jordan which enshrines the authority of the teacher and his/ her central role, which was the most dominant obstacles in this regard. The second main obstacle is the weakness of training of science teacher with regard to implementing this strategy, in addition to other obstacles related to allotted time, classroom environment and administrative obstacles. Therefore, the study recommends intensifying the training related to implementing differentiated instruction strategies, in addition to planning science curriculum in accordance with the requirements of differentiation and diversity.
\end{abstract}

Keywords: Differentiation Instruction - Science Teaching - Education Equity - Jordan.

Received: 07.12.2020 $\quad$ Accepted: 25.01.2021 $\quad$ Published: 02.02.2021

\section{INTRODUCTION}

The harmony of teaching activities with the student's characteristics, interests and attitudes are the basic features of differentiated instruction for achieving effective learning and real integration in the learning situation (Petrina,2007; Jacobs et al., 2019). The DI takes into consideration the diversity of the student's cultures, abilities, skills and trends, in addition to the various characteristics of their families (Smith \& Thorne,2007). Because the types and experiences of teaching as well as the various forms of human intelligence vary (Gardner, 2006), Gardner contends that when individuals solve problems, work through crises, and make things which are valued in their culture, they are being intelligent (Gregory \& Kuzmich, 2004). The importance of DI implementation arises in dealing with the individual differences between learners, At the same time, responding to the diversity in the methods and patterns of learning (Hobgood \& Ormsby,2011), where the response takes place through the variation in methods and styles (Koeze,2007).

John Dewy advocates the idea that the method that teachers employ in teaching should be related to the students' needs (Cunningham, 2009). The teacher can't achieve the required level of learning for all the students by using one method with all the students, since there is no single method appropriate for all the students. As for the teaching environment, the DI provides all the students with the appropriate teaching environment because it uses different methods, procedures and activities of teaching (Tomlinson, 2000) which make each student able to achieve the required goals by using the methods, activities and tools that are appropriate for him/ her (Al-Halisi, 2012).

In order to implement DI, teachers should employ gradual and diverse methods in the learning tasks in a way that suits the nature and needs of each student (Obaidat \& Abu Al-Sameed, 2009) either in learning activities or assessment activities. The curricula should also be planned with sufficient flexibility in order to be implemented with various methods and styles.

The DI increases the level of student's achievement (Tobin \& Tippett, 2014; Deunk et al., 2018), reinforces their talents and abilities, improves their trends towards learning and knowledge, raises their sense of self -responsibility (Smith \& Throne, 2007). In addition to its role in reinforcing effective 
participation since it is an access that considers the students as the center of the learning process; therefore, DI achieves the hypotheses of constructive theory (Millen \&Gable, 2016).

Despite the advantages of DI, teachers face many obstacles related to implementing it in the classroom (Acosta-Tello \& Shepherd, 2014; Corley, 2005; Schumm \& Vaughn,1991 Wan, 2015; Jager, 2017; Boston, 2017 Mariyam Shareefa, 2019; Siam, 2016; Merawi, 2018) such as:

A. Time: it is certain that diversifying teaching tasks, and the tests to understand the characteristics of students need much time which couldn't be available for teachers during work stressors.

B. Classroom environment management: DI needs a high ability and skill from the teacher to manage the classroom environment during the implementation of DI.

C. Students response: some students fail to implement the strategies restricted for DI due to their lack of knowledge about those strategies even though they are appropriate to their interest.

D. Personal teaching beliefs

Since implementing the instructional situation depends on the roles of teachers and students, the bases of DI depend on the diversification of these roles (Turner \& Thompson, 2014; Lillis, 2012). Teaching science as cognitive domain contributes to achieving this diversification; this is achieved due to the nature of the science subject (Al-Boloushi \& Ambo Sa'eedi, 2011), where there is a variety in the activities included in the Science textbook, in addition to the need of such activities to different learning aids (Zaitoon, 2007). therefore, teaching science has many opportunities to be implemented via the methods of DI.

By reviewing the previous studies, it is clear that differentiation in teaching sciences could be achieved through two paths depending on the teacher and differentiation by students (Hamil,2010; Stanford, Crowe \& Flice, 2010).

\section{Differentiation in teaching science depending on the teacher}

The science teacher can vary his instruction by means of four accesses (Trinter, Brighton \& Moon, 2015) as illustrated by Carol Tomlinson model in Figure (1)

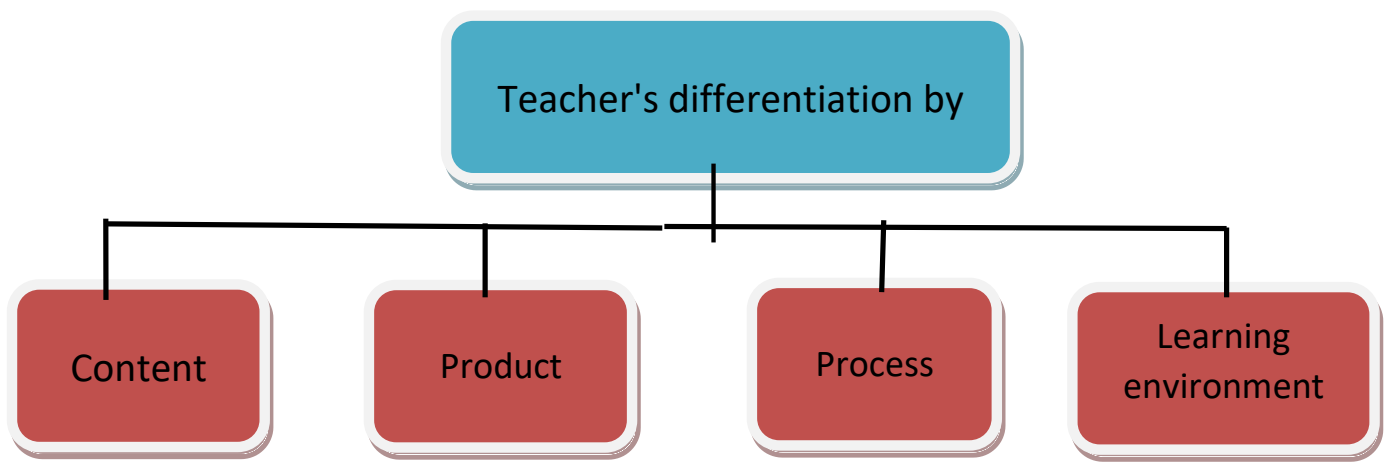

Figure 1. Tomlinson model in differentiation based on the teacher

Based on Tomlinson model, the Science teacher can vary the instruction strategies through four accesses (Tomlinson, \&Imbeau,2010) starting with the instructional content which consists a set of concepts, facts, principles, and scientific theories. The instructional goals or the educational outcomes with their three domains (cognitive, skilled, and emotional) help in using various methods and tools for achieving these goals. The third access of differentiation is the mental perceptual processes that the science teacher uses through diversification in multi thinking skills. The fourth access is represented by (learning environment); it enables the teacher of science to implement the instructional activities by means of multiple tools and conditions (Rock, Gregg, Ellis, \& Gable, 2008; Tomlinson \& Strickland,2005).

\section{Differentiation based on the students}

Tomlinson (2004) suggested that the diversity of student's interests, and the difference of their readiness and their learning styles represent an access to DI (Tomlinson,2004) (Figure .2). These differences are the base and motivation for using DI or implementing DI philosophy 


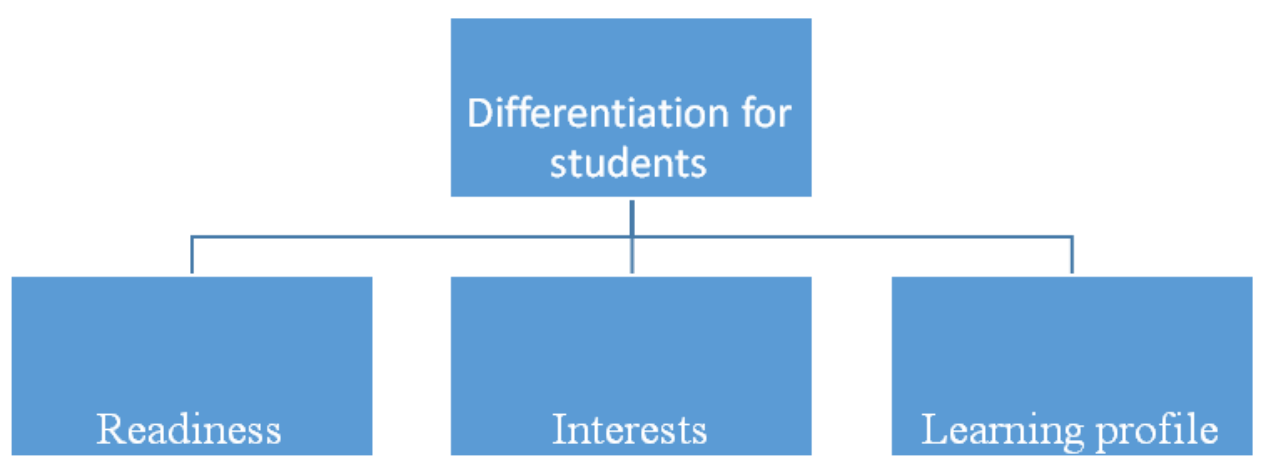

Figure 2: Tomlinson model in differentiation based on the students

The students in the classroom are different in their readiness for learning, the nature of their interest, and their learning style (Chamberlin \& Powers, 2010). The teacher of science needs time and effort to recognize the student's interests, degree of readiness, and the learning styles that suit each student. This task could be one of the obstacles towards implementing DI. This requires preparing and implementing various and multiple tests, in addition to implementing activities that demonstrate the differences between students in this domain (Gibson \& Hasbrouck, 2008; King-Shaver, 2008).

\section{Statement of the problem}

Many challenges face teaching in Jordan, including the ability of the educational system to achieve important goals, such as providing the students with the skills of thinking, problem solving, developing creative thinking reinforcing students' talents, as well as raising learner's motivation by responding to their interests and attitudes. In this regard, the DI helps achieving these goals, in addition to its role in promoting the sense of justice and equality between students which contributes to building the environment of equity in the society. Teaching science is characterized by the existence of many opportunities in implementing DI due to the variety of cognitive content and learning activities, in addition to the various learning environments, such as classroom, laboratory, garden... etc. Therefore, this study aims to recognize the opportunities and obstacles of implementing DI by science teachers in Jordan.

\section{The study significance}

The importance of this study lies in highlighting a method of teaching which could be employed to deepen the values of democracy and human rights, such as justice and equality which would, in turn, contribute to achieving the high goals of learning, especially teaching science, beside the impact of this method on academic achievement and the trends of students towards learning. Therefore, the study role in investigating the obstacles for implementing this strategy in teaching sciences locally helps in reducing these obstacles and focusing on the ways for implementing DI.

\section{The study methodology}

In order to achieve the study objectives and answer the study questions, the researchers used the descriptive design, where (18) male and female teachers of science were interviewed in Ma'an in the south of Jordan. They were randomly chosen from a group of teachers who were trained in (DI). Arrangements were made in order to interview each teacher alone. This method was adopted because of its priority and feasibility with regard to the validity of all the targeted information. The study sample due to its closeness to the researcher place of work.

Table (1) shows a description of the study sample:

Table 1. The characteristics of sample

\begin{tabular}{|l|l|l|l|}
\hline $\begin{array}{l}\text { Experience/ } \\
\text { Years }\end{array}$ & Number & Gender & Number \\
\hline $6-3$ & 5 & Male & 10 \\
\hline $6-10$ & 9 & Female & 8 \\
\hline More than 10 & 4 & Total & 18 \\
\hline
\end{tabular}

\section{The study tools}

The researcher used the interview that included direct and open questions as a tool for this study in order to recognize the perspectives of science teachers towards the implementing of DI. The study tool was 
prepared after reviewing similar previous studies, and it was also judged by a group of specialists in teaching. At the beginning of the interview, the teachers were provided with a detailed explanation about DI and its implementation requirements. Selected videos about DI were also sent to teachers via their sites in social media. Then, every teacher was asked (12) question alone. The answers were documented after recording them by the electronic recorder.

The questions of the study were distributed into three domains:

- The first domain: the educational philosophy of the teacher and his/ her trend towards DI

- The second domain: the opportunities of implementation

- The third domain: the administrative and technical obstacles towards implementation.

\section{RESULTS AND DISCUSSION}

After collecting and analyzing the data in pre-determined categories, the study concluded the following results:

\section{Teachers' philosophy and attitudes towards DI}

The interview question in this domain aimed at teachers' philosophy which motivates them to implement the strategies of DI. After explaining the details of DI implementation for teachers, the responses of (12) teachers $(67 \%)$ of the sample were negative towards DI.

They indicated that the requirements for implementing this strategy in the classroom are difficult because they were afraid of disorder and lack of control. They suggested that the method of teaching based on the teacher's role as the center of the educational process is more suitable for the nature of the classroom and the normal practices of students. therefore, the responses of the teachers in the sample reflect their traditional philosophy towards teaching.

The teachers also refrain from implementing teaching strategies that require more efforts and burdens (Prain et al., 2013), such as differentiated instruction that need good knowledge of the characteristics of students, and the organization of education groups according to these characteristics, in addition diversifying activities and evaluation methods.

R E: certainly, there will be disorder and distraction from the lesson objectives.

EE: the modern methods didn't prove their feasibility.

Kh: students are not accustomed to this method.

However, other (3) teachers stated that this strategy could be effective and productive. They suggested that they usually practice different styles of teaching. They do their best in order to implement the activities which urge the students to practice according to their tendencies and interests. Teachers hope that they would apply this strategy in teaching Science later on. This ratio of teachers represented $(17 \%)$ and they were all females.

Mu: I usually use multiple styles in presenting the concepts (Diagrams, pictures, cutters, experiments, ...etc.).

Km: I ask students to implement different activities (experiments, file completion, article).

Is: I wish I could implement this strategy and I hope that more training courses are held in this regard.

This result could be explained in terms of the philosophy of science teachers related to applying DI, in that the teachers basically taught by the traditional methods. Moreover, they used to teach using the teaching methods where the teacher has a central role in the educational process (Smith \& Tyler, 2011; Troxclair, 2013). This finding could also be explained by the teachers' belief that the traditional method gives them the control over the educational situation.

\section{B- The implementation opportunities}

Ten of the science teachers (7 males and 3 females) (56\%) of the study sample indicated that the implementation of DI may be non-existent in the reality of education in their work at class room. (39\%) of the science teachers did not show any interest in attending advance training courses to acquire the skills of DI. Moreover, (5) teachers (2 male and 3 female) suggested that the opportunities of implementing DI are possible in the light of pre-controlled circumstances and terms, while (9) science teacher (6 female and 3 male) (50\%) of the sample demonstrated a high tendency towards implementing DI after having a suitable training. These results agree with studies that demonstrated the impact of gender on the motives of being interested in the quality of education and the commitment to continuous development 
(Jordanian Department of Statistics, 2016). This indicates that there is a general problem in the education system in Jordan which represents a big challenge that needs to be dealt with.

\section{C-Obstacles of using DI in teaching}

The science teachers in the study sample suggested that the time allocated for implementing the academic curriculum does not contribute to applying DI in addition to the lack of financial and physical potentials which are appropriate for this method in the learning environment. (11) teachers in the study sample pointed out that few students have special tendencies and interests which make this method appropriate for the talented and gifted students. (8) teachers of the sample confirmed that school administrations don't prefer implementing this method due to its consequences and such conviction about the nature of DI obstacles prevalent among the science teachers are shared with teachers in general in many countries throughout the world as illustrated by (Joseph, et. al 2013).

Here are some responses of the study sample individuals:

Fi: this method needs much time and the curriculum can't be implemented in the allocated time.

Kh: I don't think that the interests and tendencies of students will be taken into consideration in the science class.

Ah: school administrations don't prefer implementing this method because of the financial requirements and the mess that could result from giving freedom to students.

The negative attitudes of school administrators towards implementing new teaching strategies comes due to fear of going out of the ordinary in the classroom (Siam \& Al-Natour, 2016), or that they believe these strategies require more procedures and expenses, so they oppose implementation this strategies and do not provide teachers with appropriate support (Jones, Yssel \& Grant, 2012; Orr, 2009; Roiha, 2014).

Generally, we can say that the science teachers in Jordan believe in the policy of teaching which is based on the central role of the teacher and the limited roles of students in the process of learning.The teachers of science don't realize the role of education in constructing the values of democracy, justice and equality in the society - and this makes the opportunities of DI very weak unless teachers are given training courses in order to develop their vision towards the role of teaching science and develop their skills for implementing this method. This result demonstrates a shortage in the Jordanian educational system with regard to forming the learning society whose individuals are committed to developing themselves and their abilities.

In the domain of obstacles, the results shows that there are many obstacles towards applying DI. In addition to teachers philosophy towards DI and their convictions that few students have certain interests and talents that could be discovered (Fuchs, 2010), we find that there isn't sufficient time for instruction, weak training and qualifying, the poor teaching environment, as well as the convictions of school administrations and the lack of support provided by these administrations to implement DI. Therefore, it is necessary to inform the educational administrations about the details of DI in order to support the implementation of this method in the correct way (Regional Education Laboratory MidAtlantic, 2015). Facing these obstacles also requires shifting from the traditional training for teachers, in addition to reinforcing the learning environment to become student-centered instead of being teachercentered.

\section{RECOMMENDATIONS}

In the light of the results, the study recommends the following:

1- Developing the science curriculum in order to be harmonious with DI requirements.

2 - providing the qualitative training for the teachers of science to modify their conventions and visions towards the goals of teaching science.

3 - Training and qualifying the teachers to deal effectively with the available environment and to employ it in DI.

4 - Involving the school administrations in the training courses of DI.

5 - Conducting further studies and researches in order to investigate the mechanisms for facilitating the implementation of DI in teaching science. 


\section{REFERENCES}

Acosta-Tello, E. \& Shepherd, C. (2014). Equal access for all learners: differentiation simplified. Journal of Research in Innovative Teaching, 7(1), 51-57.

Al-Boloushi, S. \& Ambu sa'idi, A. (2011). The methods of teaching science, practical concepts and applications. Dar Al-Maseera for publishing, distribution and printing. Amman. Jordan.

Al-Halisi, H. (2012). The Impact of Using the Differentiated Education Strategy on Academic Achievement in the English Textbook for Sixth Grade Students, (unpublished) Master Thesis, Umm Al Qura University. Makka Al-Mukarramah, the Faculty of Education.

Boston, A. (2017). An Action Research Study of Barriers to Differentiated Instruction in Reading for Georgia Middle School Students in the Inclusive Classroom. (PhD Thesis). United States of America.

Chamberlin, M. \& Powers, R. (2010). The Promise of Differentiated Instruction for Enhancing the Mathematical Understandings of College Students. Teaching Mathematics and Its Applications, 29(3), 113-139.

Corley, M. (2005). Differentiated instruction: Adjusting to the needs of all learners. Focus on the Basics, Vol.7, Issue C: March. Available: http://www.ncsall.net/?id=736(June-11-2019).

Cunningham, C., A. (2009). Transforming schooling through technology: Twentyfirst-century approaches to participatory learning. Education \& Culture, 25 (2), 46-61.

Deunk M. I., Smale-Jacobse A. E., de Boer H., Doolaard S., \& Bosker R. J. (2018). Effective differentiation practices: a systematic review and meta-analysis of studies on the cognitive effects of differentiation practices in primary education. Educ. Res. Rev. 24, 31-54. 10.1016/j.edurev.2018.02.002

Gardner, H. (2006). Multiple intelligences: New horizons. New York: Basic Books.

Gibson, V. \& Hasbrouck, J. (2008). Differentiated instruction: Grouping for success. New York, NY: McGrawHill.

Hamil, K. (2010). Differentiation Instruction. ED Compass newsletter. smarttech.com/EDC. subscribe.

Hobgood, B. \& Ormsby, L. (2011). Inclusion in the $21^{\text {st }}$-century classroom: Differentiating with technology, (2011). LEARN North Carolina. Available: www.learnnc.org/lp/pages/6917.

Jacobse S. A. E, Meijer, A., Helms-Lorenz, M. \& Maulana, R. (2019) Differentiated Instruction in Secondary Education: A Systematic Review of Research Evidence. Front. Psychol. 10:2366. doi: $10.3389 /$ fpsyg.2019.02366

Jager, T. (2016). Perspectives of teachers on differentiated teaching in multi-cultural South African secondary schools. Studies in Educational Evaluation. 53, 115- 121. https://doi.org/10.1016/j.stueduc.2016.08.004

Jones, R., Yssel, N. \& Grant, C. (2012). Reading instruction in Tier 1: Bridging the gaps by nesting evidencebased interventions within differentiated instruction. Psychology in the Schools, 49(3), 210-218. doi: $10.1002 /$ pits. 21591

Jordanian Department of Statistics. (2016). Gender Issues, An Analytical Study. The Department of Statistics, General Population and Housing Census, 2015.

Joseph, S., Thomas, M., Simonette, G., \& Ramsook, L. (2013). The impact of differentiated instruction in a teacher education setting: Successes and challenges. International Journal of Higher Education, 2(3), 28-40.

King-Shaver, B. (2008). Differentiated instruction: The new and not so new. California English, 13(4), 6-8.

Koeze, A. (2007). Differentiated Instruction: The Effect on Student Achievement in an Elementary School" (2007). Master's Theses and Doctoral Dissertations. Paper 31. http://commons.emich.edu/theses/31.

Lillis, M.P. (2012). Faculty emotional intelligence and student-faculty interactions: Implications for student retention. Journal of College Retention, Research, Theory and Practice 13(2), 155-178.

Mariyam, S., Visal, M., Rohani, M., Nor Zaiham, M., \& Rosmawijah, J. (2019). Teachers' Perceptions on Differentiated Instruction: Do Experience, Qualification and Challenges Matter? International Journal of Learning, Teaching and Educational Research. 18(8).214-226. https://doi.org/10.26803/ijlter.18.8.13

Merawi, T. M. (2018). Primary school teachers' perceptions of differentiated instruction (DI) in Awi Administrative Zone, Ethiopia. Bahir Dar j Educ., 18(2), 152-173.

Millen, R., \& Gable, R.(2016). New Era of Teaching, Learning, and Technology: Teachers' Perceived Technological Pedagogical Content Knowledge and Self-Efficiency Towards Differentiated Instruction. K-12 Education. Paper 34. Available: htt://scholarsarchive.jwu.edu/k12_ed/34 (Retrieved June-11-2016).

Obaidat, T \& Abu Al-Sameed, S. (2009). Teaching Strategies in the 21st Century Teacher's, the Guide of Teacher and Educational Supervisor, (edition 2). Oman. Dar Al Fikr. 
Orr, A. (2009). New special educators reflect about inclusion: Preparation and K-12 current practice. Journal of Ethnographic \& Qualitative Research, 3(4), 228-239

Petrina, S. (2007). Advanced Teaching Methods for the Technology Classroom.ISBN13: 9781599043371DOI: 10.4018/978-1-59904-337-1.

Prain, V., Cox, P., Deed, C., Dorman, J., Edwards, D., Farrelly, C., \& Yager, Z. (2013). Personalised learning: Lessons to be learnt. British Educational Research Journal, 39(4), 654-676.

Regional Education Laboratory Mid-Atlantic. (2015). Effective differentiation: A guide for teachers and leaders. Q\&A for Carol A. Tomlinson, Ed.D. REL Mid-Atlantic Educator Effectiveness Webinar Series. Regional Educational Laboratory Mid Atlantic, Retrieved may21, 2018.

Rock, M., Gregg, M., Ellis, E. \& Gable, A. (2008). REACH: A framework for differentiating classroom instruction. Preventing School Failure, 52(2), 31-47.

Roiha, A. (2014). Teachers' views on differentiation in content and language integrated 110 learning (CLIL): Perceptions, practices, and challenges. Language and Education, 28(1), 1-18. doi: 10.1080/09500782.2012.748061

Schumm, J. \& Vaughn, S. (1991). Making adaptations for mainstreamed students: General classroom teachers' perspectives. Remedial and Special Education. 12: 18-27.

Siam, K., \& Al-Natour, M. (2016). Teacher's differentiated instruction practices and implementation challenges for learning disabilities in Jordan. International Education Studies, 9(12), 167 -181. http://dx.doi.org/10.5539/ies.v9n12p167

Smith, D., \& Tyler, N. (2011). Effective inclusive education: Equipping education professionals with necessary skills and knowledge. Prospect: Quarterly Review of Comparative Education, 41(3), 323339. doi: $10.1007 / \mathrm{s} 11125-011-9207-5$

Smith, G.E. \& Throne, S. (2007). Differentiating instruction with technology in K-5 classrooms. Washington, DC: ISTE

Stanford, P., Crowe, M.W. \& Flice, H. (2010). Differentiating with Technology," in TEACHING Exceptional Children Plus 6, 4 (2010) Article 2. Available : Retrieved March- 21-2018.

Tobin, R., \& Tippett, C. (2014). Possibilities and potential barriers: Learning to plan for differentiated instruction in elementary science. International Journal of Science and Mathematics Education, 12(2), 423-443. doi: 10.1007/s10763-013-9414-z

Tomlinson, C. (2000). Differentiation of instruction in the elementary grades. Retrieved from ERIC database. (June-11-2019).

Tomlinson, C. (2004). How to differentiate instruction in mixed-ability classrooms (2nd ed.). Alexandria, VA: ASCD.

Tomlinson, C. \& Strickland, C. (2005). Differentiation in practice: A resource guide for differentiating curriculum, grades 9-12. Alexandria, VA: ASCD.

Tomlinson, C. \& Imbeau, M. (2010). Leading and managing a differentiated classroom. Alexandria, VA: ASCD.

Trinter, C., Brighton, C. \& Moon, T. (2015). Designing differentiated mathematics games: "Discarding" the one-size-fits-all approach to educational game play. Gifted Child Today, 38(2), 88-94.

Troxclair, D. (2013). Preservice teacher attitudes toward giftedness. Roeper Review, 35(1), 58-64. doi: $10.1080 / 02783193.2013 .740603$

Turner, P. \& Thompson, E. (2014). College retention initiatives: Meeting the needs of millennial freshman students. College Student Journal 48(1), 94-104.

Wan, S. (2016). Differentiated instruction: are Hong Kong in-service teachers ready? Teachers and Teaching: Theory and Practice. 23, (3). 284-311. Retrieved from https://doi.org/10.1080/13540602.2016.1204289

Zaitoon, A. (2007). constructive theory and science teaching strategies. Dar Al-Shorouq, Amman. edition 1. ISBN 9957. 